\title{
A IMPLEMENTAÇÃO DO PRONATEC NO IFPE ${ }^{1}$
}

André Luís Gonçalves Pereira²

\section{Resumo}

O Pronatec, principal iniciativa de qualificação profissional existente no país, tem origem no primeiro governo Dilma Rousseff e se apresenta como altamente capilarizado e responsável pelo despertar de inúmeras esperanças de empregabilidade e ascensão profissional para imensos setores da classe trabalhadora, sua faceta mais visível é a oferta de cursos FIC e técnicos através da modalidade bolsa-formação. Em nossa pesquisa analisamos 0 ordenamento do IFPE para a execução destes cursos como ofertante, seus impactos na estrutura da Instituição, os efeitos da oferta de cursos muitas vezes desconectados com a história de diferentes campi. Fizemos esta análise a partir da análise documental primária e secundária além da realização de entrevistas semiestruturadas junto a gestores, docentes e egressos do Programa, notadamente os que estavam inseridos nos cursos técnicos promovidos no Campus Vitória de Santo Antão do IFPE. As dificuldades relacionadas a uma estrutura deficiente, a falta de uma concreta assistência estudantil e o comprometimento dos docentes com o Programa são importantes destaques que estão presentes nas falas destes atores.

Palavras-chave: Pronatec. IFPE. Implementação.

\section{Resumen}

El Pronatec, principal iniciativa de cualificación profesional existente en el país, fue creado en el primero gobierno de Dilma Rousseff y se presenta como presente en varias ciudades y responsable por el despertar de muchas esperanzas relacionadas a la conquista de empleo y ascenso profesional para inúmeros sectores de los trabajadores, su faceta más visible es la oferta de cursos FIC y técnicos a través de na modalidad "bolsa-formação". En nuestra investigación analizamos como el IFPE se organizó para ejecutar estos cursos, cuales sus impactos en la estructura de la institución y la oferta de cursos muchas veces no relacionados a la historia de distintos campi. Esta investigación se realizó a través del análisis documental además de la realización de entrevistas con egresados, maestros y gestores, principalmente los que participaban de los cursos técnicos del Campus Vitória de Santo Antão del IFPE. Las dificultades relacionadas a una estructura precaria, la falta de una asistencia a los alumnos satisfactoria y el compromiso de los maestros con

\footnotetext{
1 DOI: https://doi.org/10.22409/tn.15i28.p9642

${ }^{1}$ Mestre em educação. Professor e coordenador de políticas institucionais no IFPE. E-mail: andre.pereira@belojardim.ifpe.edu.br
} 
el Programa son importantes rasgos presentes el habla de estos personajes.

Palabras clave: Pronatec, IFPE, implementación.

\section{Introdução}

O Programa Nacional de Acesso ao Ensino Técnico e Emprego (Pronatec) é mais uma iniciativa estatal que busca levar a qualificação profissional aos setores mais espoliados da população. O Pronatec costuma despertar na classe trabalhadora uma grande esperança de mudança dos seus rumos profissionais. A juventude desta classe é um alvo importante do Programa, na medida em que é o setor da sociedade mais sensível ao desemprego e o maior empregado em funções precarizadas. Desta forma, a iniciativa aparece como uma maneira de superar as dificuldades de colocação no mercado de trabalho através da capacitação profissional.

Este Programa é na verdade um "guarda-chuva" para várias iniciativas no campo da educação profissional, englobando desde o investimento nos equipamentos da rede de ensino profissional de escolas estaduais até 0 oferecimento de cursos técnicos e de Formação Inicial e Continuada (FIC) através da Bolsa-Formação (a faceta mais conhecida do programa). Estes cursos são ofertados por diversas instituições públicas e privadas e chama a atenção sua presença marcante nos diversos Institutos Federais, como ocorre no Instituto Federal de Educação, Ciência e Tecnologia de Pernambuco (IFPE), onde desde o nascimento do Programa foram executados diversos cursos técnicos e FIC através desta iniciativa.

O IFPE já ofertou cursos do PRONATEC em todos os seus campi. A modalidade mais executada pelo Instituto são os cursos de Formação Inicial e Continuada (FIC). É nestes cursos, com alunos enviados pelo Ministério de Desenvolvimento Social e Combate à Fome (MDS), através do CRAS (Centro de Referência da Assistência Social) de cada município, que se encontra a porção mais marginalizada entre os estudantes da Bolsa-Formação do Pronatec. Os cursos técnicos vinculados à Bolsa-Formação foram ofertados pelo Instituto apenas nos campi de Vitória de Santo Antão e Cabo de Santo Agostinho. No primeiro Campus, cursos da modalidade concomitante demandados pela Secretaria Estadual de Educação e Esportes de 
Pernambuco (SEE-PE), e no segundo, cursos da modalidade subsequente, com oferta através do SISUTEC 2 .

O presente trabalho tem como objetivo discutir o ordenamento interno realizado no IFPE para que esta Instituição fosse capaz de abrigar cursos da modalidade Bolsa-Formação do Pronatec. Procuramos analisar o Instituto de forma global e elegemos os cursos técnicos do Campus Vitória de Santo Antão para uma análise mais detalhada.

A motivação para fazer esta pesquisa se apresenta fundamentalmente pelo fato de o Pronatec, como um Programa recém-implementado em nosso país, ser alvo crescente de pesquisas, embora estas ainda se apresentem em pequena quantidade frente ao tamanho e à complexidade desta iniciativa governamental. Nosso desejo é fazer desta pesquisa uma ferramenta para todos os envolvidos no Programa, notadamente a população que é atingida pelos impactos de suas diversas iniciativas, poderem melhor conhecê-lo e dar passos no sentido de avaliá-lo, e investigar as relações do Pronatec com outras políticas no campo social e econômico.

\section{Nosso percurso metodológico}

Em nossa pesquisa utilizamos o referencial teórico-metodológico do materialismo histórico-dialético. Triviños (1989) destaca que este referencial busca explicações coerentes, lógicas e racionais para os fenômenos naturais, sociais e do pensamento, buscando através do enfoque dialético mostrar como se transforma a matéria, estudando o que caracteriza a vida na sociedade, sua evolução histórica e a prática social humana. Nos parece que este referencial é o que está mais adequado para a nossa pesquisa, por ela necessitar de uma visão histórica sobre a sociedade e sua relação com a educação profissional, ao mesmo tempo que é importante relacionar os diversos aspectos presentes

\footnotetext{
2 Sistema de Seleção Unificada da Educação Profissional e Tecnológica. Instituído pelo Governo Federal, oferece vagas gratuitas de cursos técnicos para candidatos que participaram da última edição do Exame Nacional do Ensino Médio (Enem). Seu processo seletivo acontece duas vezes ao ano, uma vez a cada semestre, dando ao candidato a oportunidade de conseguir uma vaga em instituições públicas e privadas de ensino superior, assim como as de educação profissional e tecnológica.
} 
na realidade pesquisada, em um movimento que mostre estes aspectos dialeticamente como parte de uma totalidade social.

O entendimento do que seja o método dialético materialista inicia sua explicitação mediante a questão: como se reproduz concretamente um fenômeno social? ou seja, quais as "leis sociais", históricas, quais as forças reais que o constituem enquanto tal? esta questão indica, ao mesmo tempo, no âmbito das ciências humano-sociais, o caráter sincrônico e diacrônico dos fatos, a relação sujeito e objeto, em suma, o caráter histórico dos objetos que investigamos (FRIGOTTO, 1989 p.78).

Esse referencial teórico-metodológico nos potencializa para a descoberta das contradições no processo de implementação do PRONATEC, em uma visão contextualizada, onde a história, as relações sociais, as relações de poder e as contradições estão presentes por todo o percurso. Ao mesmo tempo, por ter este referencial como basilar, compreendemos que os resultados de nossa investigação são sempre passíveis de questionamentos, como toda pesquisa deve ser, pois para o materialismo dialético a ciência compreende movimentos contínuos.

Se as verdades científicas fossem definitivas, a ciência teria deixado de existir como tal, como investigação, como novas experiências, reduzindo-se a atividade científica à repetição do que foi descoberto. O que não é verdade, para felicidade da ciência. Mas, se nem mesmo as verdades científicas são definitivas e peremptórias, também a ciência é uma categoria histórica, um movimento em contínua evolução [...] toda a ciência é ligada às necessidades, à vida, à atividade do homem (GRAMSCI, 1978, p. 70).

Fizemos seleção dos documentos necessários para subsidiar nossa pesquisa. Consideramos documento qualquer registro escrito que possa ser usado como fonte de informação (ALVES-MAZOTTI e GEWANDSZNAJDER, 2002). Dividimos os documentos segundo a classificação de Duffy (2010), que destaca que estes podem ser fontes primárias ou secundárias. As primárias são destacadas pelo pesquisador como as que sejam produzidas durante 0 período a ser investigado, já as secundárias consistem na interpretação de eventos deste período. 
Outro instrumento de análise foram as entrevistas semiestruturadas. Neste instrumento não se espera a limitação das respostas dos entrevistados nem que respondam a tudo da mesma maneira, sendo o entrevistador livre para deixar os entrevistados responderem as questões da maneira desejada, oferecendo a oportunidade para qualquer esclarecimento (MOREIRA, 2006). Realizamos estas entrevistas com 12 egressos (seis de cada curso técnico investigado), 03 docentes, 02 gestores do Pronatec no Campus Vitória de Santo Antão, a gestora da escola estadual onde os egressos cursaram o ensino médio, o coordenador do Pronatec na SEE-PE e a coordenadora geral do Pronatec no IFPE. Estas entrevistas foram realizadas por um período de três meses, havendo a necessidade de visitar nove egressos em suas casas e três egressos em seus locais de trabalho. A totalidade dos docentes e gestores foi entrevistada em seus locais de trabalho, havendo uma boa receptividade para com o pesquisador da parte de todos, o que muito facilitou nossa investigação.

\section{O Pronatec}

O Pronatec teve início em 2011, através da lei n. 12.513, materializando um ambicioso Programa de qualificação profissional. Programa desenvolvido com uma série de ações voltadas ao ensino técnico e profissionalizante e altamente capilarizado, já que até $2016,72,3 \%$ dos municípios brasileiros ofertavam ou haviam ofertado cursos relacionados ao Pronatec.

A lei n. 12.513/2011 foi modificada pela de n. 12.864/2013, com o objetivo de ampliar o rol de beneficiários e ofertantes da Bolsa-Formação Estudante, no âmbito do Programa Nacional de Acesso ao Ensino Técnico e Emprego - PRONATEC (BRASIL, 2013). Essa alteração teve como principal objetivo incluir no Programa instituições de ensino privadas, como se explicita em seu artigo terceiro:

O Pronatec cumprirá suas finalidades e objetivos em regime de colaboração entre a União, os Estados, o Distrito Federal e os Municípios, com a participação voluntária dos serviços nacionais de aprendizagem, de instituições privadas e públicas de ensino superior, de instituições de educação profissional e 
tecnológica e de fundações públicas de direito privado precipuamente dedicadas à educação profissional e tecnológica, habilitadas nos termos desta Lei (BRASIL, 2015).

No Brasil, historicamente se apresentam programas que servem para ofertar de forma precarizada o conhecimento estrito para o desempenho das funções dos que vivem do seu trabalho, em consonância com os desejos dos capitalistas. O acesso dos trabalhadores a um saber parcial interessa ao capital, pois este espera um corpo de operários minimamente qualificados, de acordo com suas necessidades (GORZ, 1980). É dentro dessa dialética entre o não oferecer de conhecimento completo e integrado e a necessidade de rudimentos básicos para o exercício da maior parte das ocupações ofertadas no mercado de trabalho que se fortalecem os programas de profissionalização como o Pronatec. É também necessário ressaltar a desqualificação do trabalhador como interessante ao capitalista, pois o operário, ao dominar 0 conteúdo do trabalho, passa a ter mais poder de reivindicação dentro do espaço onde trabalha (KUENZER, 1985).

Os governos que sucederam a gestão de Fernando $H$. Cardoso se caracterizaram pelo empenho em defender a ideia de que nos seus mandatos existiram iniciativas concretas no sentido da efetiva expansão do número de escolas profissionalizantes e do maior acesso à formação profissional. 0 projeto educacional gestado por estes governos se origina de uma crítica ao governo gerido pelo PSDB, por ter sido deste a iniciativa de não mais construir escolas técnicas e realizar nos antigos CEFETs uma política de dicotomia entre o Ensino Médio e a Educação Profissional. Dilma Rousseff fez da expansão da Rede de Educação Profissional e das demais iniciativas neste campo, de responsabilidade de seu governo e da gestão capitaneada por Lula da Silva, um importante fator de propaganda em suas duas eleições à presidência da república.

Não se pode negar a popularidade e a aceitação do Pronatec junto à classe trabalhadora. Essa repercussão positiva no imaginário da classe espoliada está relacionada diretamente à propagação da Teoria do Capital Humano, francamente hegemônica e colocada como imparcial e acima das ideologias. Segundo Frigotto (1997), a noção ou teoria de capital humano foi 
elaborada nos anos de 1956-57, por Theodoro Schultz, buscando explicar os acréscimos à produção que não mais podiam ser compreendidos através dos conceitos antes utilizados para avaliar capital e trabalho. Uma grande massa de estadounidenses investia maciçamente em suas carreiras e Schultz foi observando estes investimentos tendo significativa influência sobre o crescimento da economia. Assim, o investimento em "si mesmo" notadamente em capital e saúde foi chamado de "capital humano". A partir desta observação é elaborada a Teoria do Capital Humano.

Consequentemente, não podemos ver o Pronatec como uma iniciativa isolada e original, já que este Programa, como seus antecessores, não considera o desemprego como manifestação do capital mundializado, o qual intensifica o trabalho humano e precariza as relações do trabalho, produzindo $o$ desemprego estrutural (Silva, Lucena e Ferreira, 2011). No lugar disso, esta iniciativa governamental, em sintonia com a Teoria do Capital Humano, responsabiliza o trabalhador pela sua situação dentro do mercado de trabalho.

Em nosso país, planos como o PRONATEC visam dar uma continuidade a uma política de formação desconectada de uma educação geral, aprofundando a dicotomia entre os que "pensam" e os que "fazem", sendo bastante útil para a perpetuação de nossos abissais conflitos sociais.

O resultado de políticas de profissionalização como o PRONATEC é um misto de alento para os setores mais precarizados e reforço da política que coloca o Brasil na periferia do capitalismo e esses setores na marginalidade do processo de desenvolvimento.

Se você pega alguém que veio da informalidade, que estava nos grotões da miséria e do subdesenvolvimento e lhe ensina a prestar uma informação sobre um evento de Copa do Mundo, por exemplo, ela sente isso como um progresso, no entanto, do ponto de vista agregado, global, do país, isso reproduz as bases desse neo-subdesenvolvimento, que se caracteriza justamente por postos de trabalho muito mal remunerados e subqualificados (BRAGA, 2013).

\section{A implantação do Pronatec no IFPE}

Como membro da Rede Federal de Educação Profissional e Tecnológica o IFPE é executor de diversos cursos no âmbito do Bolsa-Formação do 
Pronatec, além de receber o impacto de outras iniciativas do Programa. Para uma execução mais eficiente do Programa no interior do IFPE, uma série de documentos foram formulados e aprovados: Resolução no 47/2014 (aprova 0 regimento interno das ações da bolsa-formação do Pronatec no Instituto), Regimento interno das ações da bolsa formação do Pronatec no IFPE, Nota orientadora $n^{\circ}$ 001/ 2014 (assunto: pagamentos de bolsas/horas trabalhadas), Nota orientadora no 002/ 2014 (assunto: estabelece normas, procedimentos e modelos de documentos para realização de visitas técnicas no âmbito da bolsa formação Pronatec/IFPE), Nota orientadora № 002/ 2015 (assunto: estabelece modelo de declaração para os bolsistas do PRONATEC/IFPE nas funções docentes e administrativas). A Pró-Reitoria de Extensão do Instituto é a responsável pela implementação do Pronatec.

De todos os documentos citados, o mais importante é o Regimento Interno que disciplina as ações da Bolsa-Formação no IFPE. Aprovado em 2014 (três anos após a implantação do Pronatec no Instituto), tem como principal objetivo regulamentar a atuação do Programa, servindo como complementação da legislação estabelecida a nível nacional.

A Bolsa- Formação do PRONATEC no IFPE é executada por um comitê gestor na Reitoria e por comitês executivos, nos diversos campi em que ele é ofertado.

Art. 3ํ. O Comitê Gestor Bolsa Formação do PRONATEC é composto pelos seguintes agentes, com as respectivas competências, no âmbito do IFPE: I. Reitor(a): Presidente do Comitê; II. Coordenador(a)-Geral da Bolsa Formação do PRONATEC: vice-presidente do Comitê, representante do IFPE junto ao MEC, no âmbito da Bolsa Formação do PRONATEC, e responsável pela gestão, coordenação, orientação, seleção e execução da Bolsa Formação do PRONATEC e demais atribuições previstas em Resolução específica do FNDE. III. Coordenador(a) Adjunto(a) da Bolsa Formação do PRONATEC: responsável por assessorar o Coordenador-Geral nas ações relativas à Bolsa Formação do PRONATEC e substituí-lo em período em que estiver ausente ou impedido e demais atribuições previstas em Resolução específica do FNDE. IV.Pró-Reitor(a) de Extensão: responsável pelas políticas institucionais de extensão, pela supervisão e planejamento da oferta anual de vagas de cursos FIC e pela articulação interna e externa no âmbito da Bolsa Formação do PRONATEC. V. PróReitor(a) de Ensino: responsável pelas políticas 
institucionais de ensino e pela supervisão e planejamento da oferta anual de vagas de cursos Técnicos no âmbito da Bolsa Formação do PRONATEC. VI. Pró-Reitor(a) de Administração: responsável pelas políticas institucionais de administração e pela supervisão da execução orçamentária e financeira das atividades relacionadas à Bolsa Formação do PRONATEC.

Art. 4ํ. Cada Comitê Executivo da Bolsa Formação do PRONATEC é composto pelos seguintes agentes, com as respectivas competências no âmbito dos Campi do IFPE: I. Diretor-Geral: Presidente do Comitê; II. Coordenador-Adjunto da Bolsa Formação do PRONATEC no Campus: vicepresidente do Comitê: responsável pela oferta da BolsaFormação no Campus da Instituição, pelo desenvolvimento, avaliação, adequação e ajuste da metodologia de ensino adotada, pela execução orçamentária e financeira das atividades relacionadas à Bolsa Formação do PRONATEC e demais atribuições previstas em Resolução específica do FNDE. III. Diretor de Ensino: responsável pelo planejamento da oferta anual de vagas de cursos Técnicos no âmbito da Bolsa Formação do PRONATEC. IV. Diretor de Extensão ou instância equivalente: responsável pelo planejamento da oferta anual de vagas de cursos FIC no âmbito da Bolsa Formação do PRONATEC. V. Diretor de Administração: responsável pela execução orçamentária e financeira das atividades relacionadas à Bolsa Formação do PRONATEC (IFPE, 2014, p. 3-4).

Cabe aos comitês executivos a gestão dos recursos de forma compartilhada com o comitê gestor. Estes comitês podem contar ainda com coordenadores, supervisores e pessoal de apoio, assim como o comitê gestor pode contar com profissionais de apoio e supervisão. Estes profissionais, que podem participar da execução e gestão do Programa, assim como o coordenador geral e os coordenadores adjuntos (indicados pela Reitoria), recebem remuneração para o desenvolvimento de funções relativas ao programa, ao contrário dos demais que são membros natos.

Os diferentes cursos FIC e técnicos oferecidos pelo IFPE através do Pronatec têm o seu projeto pedagógico elaborado de maneira prévia. Os professores anteriormente recebiam este projeto pronto, assim como o plano de suas disciplinas, mas são agora os responsáveis pela elaboração dos planos do curso que vão ministrar, de acordo com os editais responsáveis pela seleção docente, publicados a partir de 2015.

Há uma política no IFPE conectada com as diretrizes nacionais do Programa para a assistência aos estudantes. 
Art. 28. O IFPE deverá criar mecanismos de acompanhamento e de assistência que permitam o acesso, a permanência e a conclusão de cursos técnicos e FIC aos beneficiários das atividades da Bolsa Formação do PRONATEC. Art. 29. A assistência estudantil ofertará os seguintes benefícios: I. Fardamento (camisa da Instituição); II. Alimentação (repasse financeiro); III. Materiais didáticos/ escolares gerais ou específicos; IV. Transporte para os estudantes que não têm transporte escolar gratuito disponível (repasse financeiro). V. Seguro contra acidentes (IFPE, 2014).

- Essa política se mostra muito importante para a permanência dos alunos nos cursos ofertados, porém sua execução plena nem sempre se apresenta de maneira satisfatória como atestam os seguintes depoimentos de gestores e discentes de cursos técnicos ofertados pelo IFPE através do Pronatec quando questionados se havia atraso no pagamento do auxílio financeiro, necessário para o deslocamento do estudante e também para sua alimentação:

Muitos meses teve confusão, atraso e até mesmo falta mesmo, porque o IFPE era desprovido. É como se o Instituto tivesse dificuldade por algum motivo, não sei se distância, não sei se era devido à política, politicagem, não sei explicar ao certo, mas em alguns momentos teve algumas polêmicas, porém depois foi ressarcido (Gestor1).

Era até um problema que a gente sempre tinha, porque os alunos vinham e aí a gente falava: olha nem a nossa foi paga. Não pensem que a gente tá recebendo $e$ vocês não. Sempre houve atraso. A gente recebia assim, três, quatro bolsas de uma vez ((Gestor 2).

Foram pagos, regularmente não. Geralmente atrasava 3, 4 meses. A gente nunca sabia quando ia sair esse auxílio, sempre atrasava, sempre! Era sempre sem previsão (Estudante 1).

Ficavam três, quatro meses atrasando e nunca vinha certo (Estudante 4).

Não. Nunca foi pontualmente. Às vezes a gente recebia um "mês dentro", às vezes demorava dois meses, aí a gente ia e recebia (Estudante 5).

Foram pagos, regularmente não. Geralmente atrasava 3, 4 meses, a gente nunca sabia quando ia sair esse auxílio, sempre atrasava, sempre, era sempre sem previsão (Estudante 11).

Todos os 16 campi do IFPE onde são ou já foram cursos da Bolsa- 
Formação tem a obrigação de atuar como ofertante, e as instituições credenciadas pelo MEC atuarão como parceiros demandantes. Cabe a cada Campus do IFPE pactuar no sistema SISTEC os cursos e a quantidade de turmas e de vagas por turma disponíveis para a oferta. Cabe a cada parceiro selecionar os estudantes e trabalhadores para os cursos (IFPE, 2015). Até 2014 existia uma discussão conjunta entre cada unidade do IFPE e os demandantes sobre os cursos que deveriam ser ofertados, de acordo com as necessidades diagnosticadas pelo demandante e as possibilidades do Instituto. A partir de 2015 o demandante passou a ser o único responsável pela seleção dos cursos a serem ofertados em cada localidade. Segundo a coordenação geral do Pronatec-IFPE, isso fez alguns campi não oferecerem ou oferecerem menos cursos que o possível pela simples razão de os cursos desejados pelos demandantes não terem condições estruturais de serem oferecidos naquelas unidades. O curioso é que em muitas ocasiões, como não havia nenhum ofertante com capacidade de ministrar os cursos desejados pelos demandantes (predominantemente prefeituras), simplesmente não era ofertado nenhum curso do Pronatec Bolsa-Formação naquela localidade.

Em 2015 o IFPE ofertou apenas 589 vagas, distribuídas em 11 cidades. Neste ano não houve oferta de vagas para nenhum curso técnico, todos os cursos ofertados foram da modalidade FIC. A redução orçamentária impediu o crescimento do número de cidades atendidas e de cursos ofertados, já que em 2012 houve 1.300 matrículas em 9 cidades para 67 cursos. Em 2013, um substancial crescimento para 4.966 matrículas, 200 cursos ofertados e 12 municípios atendidos. Em 2014 foram 3.421 matrículas de Bolsa-Formação no Pronatec na Instituição, ofertadas por todos os 16 campi do Instituto em 18 cidades (Abreu e Lima, Igarassu, Afogados da Ingazeira, Barreiros, Tamandaré, Paulista, São José da Coroa Grande, Belo Jardim, Olinda, Cabo de Santo Agostinho, Ipojuca, Jaboatão dos Guararapes, Caruaru, Garanhuns, Palmares, Pesqueira e Vitória de Santo Antão). A diferença entre o número de cidades impactadas e os campi ofertantes é pelo fato de o Campus de Barreiros ofertar cursos em São José da Coroa Grande e Tamandaré.

Até o ano de 2015, foi investido na Bolsa-Formação do Pronatec do 
IFPE a quantia de $\mathrm{R} \$ 30.365 .604,00$. No ano de 2013 tivemos o maior número de recursos destinados ao Programa $(R \$ 8.416 .378,00)$, seguido de $2014(R \$$ $5.776 .426,00)$ e 2012 ( $R \$ 5.047 .200,00)$. No ano de 2015, como consequência da redução de orçamento promovido pelo Governo Federal, o orçamento destinado é de apenas $R \$ 1.581 .576,00$, o menor ao longo de todos os anos (menos de $20 \%$ do orçamento destinado no ano anterior). Essa redução drástica do orçamento resultou em uma menor quantidade de vagas oferecidas, apenas 589 vagas, e menos cidades atendidas, já que apenas 10 municípios foram contemplados com cursos do Pronatec ofertados pelo IFPE.

Os cursos do Programa se estabelecem nas unidades educacionais sem nenhuma relação com os cursos regulares ofertados nas mesmas. Isso acontece notadamente nos Institutos Federais, onde o seu projeto de ensino médio integrado é contraditório ao que se estabelece com o Pronatec.

\begin{abstract}
Um programa que "caiu" na conta dos Institutos Federais, em específico, não fazendo parte naturalmente da estrutura organizacional administrativa e pedagógica que estas instituições possuem. Paliativa, ainda, considerando a temporalidade do programa, pensado e colocado em atuação com uma estrutura de pagamento de pessoal como forma de bolsa, que precariza a atuação docente e coloca o professor numa situação de refém de uma condição de trabalho sem garantias e direitos (SANTOS, 2013).
\end{abstract}

Esta não integração com os cursos ofertados regularmente pela instituição é algo que precariza sensivelmente os cursos ofertados, notadamente os cursos técnicos, pela inexistência de estrutura adequada para o desenvolvimento dos trabalhos educacionais, a oferta do curso de técnico em Segurança do Trabalho no Campus Vitória de Santo Antão já previa desde sua concepção que não havia estrutura adequada para o mesmo, o que devia ser compensado com viagens para outros campi do IFPE:

Para atender as necessidades de aulas práticas essenciais à formação do Técnico em Segurança do Trabalho, o Campus possui laboratórios de Informática e realizou parceria com 0 Campus Caruaru, que dispõe dos seguintes laboratórios: 1. Laboratório de Higiene Industrial e Medicina do Trabalho; 2. Laboratório de Proteção Contra Incêndio [...] o Campus Vitória de Santo Antão conta com uma biblioteca que atende a totalidade dos cursos técnicos atualmente ofertados. Com 
relação ao acervo específico para o curso de Segurança do Trabalho, utilizaremos, por meio de parceria firmada, a biblioteca do Campus Caruaru (IFPE, 2012).

Quando o curso foi executado os estudantes deste curso técnico notaram a ausência de equipamentos para um desempenho satisfatório, assinalando inclusive a diferença entre o que era ofertado para este curso e o que era oferecido aos estudantes do curso técnico de alimentos:

A infraestrutura eles não deram a gente. [...] Técnico em Alimentação tinha toda infraestrutura, lá porque eles já têm ali alimento, já têm tudo. A gente não, não tinha infraestrutura igual ao que o Técnico de "Alimentação" tinha (E2ST).

O Campus Vitória de Santo Antão oferta de maneira regular o curso de técnico em agroindústria, que tem uma matriz curricular e infraestrutura muito semelhantes ao curso técnico em alimentos, se apresentando assim como um curso não inteiramente desconectado do que tradicionalmente é ofertado no referido Campus. Por isso a percepção de haver uma qualidade diferenciada. Diversos outros depoimentos de alunos chamam a atenção para a estrutura altamente deficiente para os futuros técnicos em segurança do trabalho:

A gente tinha que sair porque lá não tinha... [...] implantaram o curso, mas não tinha uma estrutura qualificada para [...] o curso de Segurança do Trabalho. Por exemplo, a gente não teve a disciplina de Combate a Incêndio, que é uma das principais da área (Estudante 5).

Lá no IFPE Vitória, não tem laboratório para o Técnico de Segurança do Trabalho. O refeitório era fechado à noite, e a gente só ficava nas salas mesmo. As salas eram climatizadas e dava pra você assistir aula normalmente (Estudante 4).

As salas de aula são todas equipadas, são boas, a biblioteca também [...] só o que a gente não achava legal era a maioria dos laboratórios. Porque tinha equipamento que tava lá parado, como eu já disse, a gente foi fazer o mapa de risco, e a gente viu muita coisa irregular nos laboratórios (E 6). 
Podemos observar nas falas um desencanto com o ofertado ao curso escolhido, mas um desencanto que se relaciona a um reconhecimento da estrutura física geral do Campus, como assinala a Estudante 5 " as salas de aula são todas equipadas (...) a biblioteca também".

Além da ocorrência de oferta de cursos não relacionados aos ofertados regularmente pelos Campi, ainda há a problemática da precarização da oferta. Os Institutos Federais, assim como as escolas que os antecederam, são reconhecidos pela sociedade como Instituições ofertantes de um ensino de qualidade, e esta constatação é por vezes paradoxal às condições ofertadas para os alunos do Programa. NOVAES (2013), ao analisar a instalação do Programa no IFPR, constatou que as verbas para materiais e equipamentos não foram pensadas antecipadamente. As nossas pesquisas no IFPE Campus Vitória de Santo Antão nos levaram a conclusões bastante similares, já que, notadamente os alunos, constatavam a ausência de material de trabalho como equipamento de proteção individual ou insumos essenciais para o desenvolvimento dos cursos, como atestam os depoimentos seguintes.

A infraestrutura da agroindústria que deixou um pouco a desejar porque nós sentimos um pouco de dificuldade. Questão de empecilhos que a gente tinha pra fazer a prática. Tudo que a gente aprendeu na teoria tinha que fazer na prática só que a gente tinha que um pouco mascarar aquilo com 0 que tinha.......] vou dar um exemplo, se a gente tinha que ter um piso abaulado, na agroindústria não tinha. Só que a gente sabia o certo, mas na prática nós não víamos o certo (Estudante 10).

As botas, a gente teve que comprar. E o capacete, o coordenador comprou e deu. Agora o resto foi por conta da gente: $O$ óculos e os materiais que a gente usava pro estágio (Estudante 5).

No início a gente teve dificuldade com a renda. Aí a bota a gente teve que investir pra que as aulas práticas começassem mais cedo. A gente comprou a bota, a gente comprou jaleco, touca pra nosso uso... a turma de segurança só teve que comprar a bota, pois o resto dos equipamentos foram tudo ganhos (E 12).

A parte teórica eles davam os materiais, mas a parte prática a gente é que comprou os materiais, tipo a bota, o que necessitava a gente comprava para fazer a aula. Se faltasse alguma fruta, alguma coisa bem básica, a gente se reunia e fazia cota, mas geralmente tinha tudo lá. Já faltou 
coisa básica que a gente precisava nas aulas práticas da gente: roupa branca, bota. Isso a gente não ganhou, a gente teve que tirar de nosso bolso, diferente da turma de segurança do trabalho, que recebeu esses materiais didáticos (E2).

A gente só recebeu capacete. A bota [...] tinha que comprar, porque não tinha como conseguir lá. A gente só recebeu lá o capacete (E3).

Além do oferecimento da Bolsa-Formação, modalidade mais visível e predominantemente associada pela população em geral como única iniciativa do PRONATEC, a expansão do IFPE, prevista como uma das iniciativas do Programa, provocou a criação dos novos campi de Paulista, Igarassu, Abreu e Lima, Jaboatão dos Guararapes, Cabo de Santo Agostinho e Palmares. A criação destes campi corresponde à terceira fase de expansão da Rede Federal de Educação Profissional e Tecnológica, instituída pela Lei no 11.195/2005. Todas as unidades educacionais frutos desta terceira expansão funcionam em prédios alugados ou cedidos, um dos indícios da falta de estrutura que acompanha esta expansão. A precarização da expansão do Instituto já havia sido constatada em relatório do Tribunal de Contas da União, publicado em 2013, que constatou que "no IFPE houve um grande aumento do número de alunos sem o correspondente acompanhamento de infraestrutura, sobretudo no que diz respeito à quantidade de salas de aula" (TCU, 2013).

Outro importante fator para ilustrar a precarização da expansão da Rede Federal de Educação Profissional, Científica e Tecnológica é o quadro de docentes e técnicos. Mesmo considerando a notável contratação de servidores ocorrida nos últimos anos através de sucessivos concursos públicos, estes ainda se mostram insuficientes para a demanda existente. Como resultado desta realidade, houve a abertura de campi do IFPE sem um quantitativo adequado de técnicos e docentes necessários ao bom funcionamento da Instituição. Alguns campi entraram em funcionamento predominantemente com os contratados pelo Pronatec (tal fato ocorreu em Abreu e Lima, Jaboatão dos Guararapes e Cabo de Santo Agostinho). Com relação a este movimento, Schewede e Lima Filho (2015) constataram que ocorre um processo de expansão destas instituições a baixo custo, com contingenciamento de professores e elevação da relação de alunos por professor. Na unidade em 
que fizemos as entrevistas os docentes eram todos servidores públicos do IFPE o que os levava a considerar os proventos recebidos pelo Programa como um dinheiro extra. Os mesmos docentes acreditavam na proposta do Pronatec e assinalavam sua importância:

Eu atuei em três cursos FIC como professor e recebi o convite para ser gestor. Então recebi o convite da direção [...] A motivação foi em contribuir mesmo com a ideia do programa (G1).

Eu sou professor por vocação mesmo. Eu nasci pra isso. É o desafio de aumentar nossa clientela, foi esse o grande desafio, de atender a um cliente, um aluno, um estudante de outra Instituição de Ensino [..] Acho que foi isso (D3).

Eu fui convidado pelos professores da Agroindústria a apresentar a minha documentação pra concorrer. Eu sabia que existia uma vaga, inclusive eu tava com uma carga horária apertada, mas eu tive intenção de entrar justamente pra colaborar pra que o curso efetivamente se realizasse. Tinha necessidade, tava sem professor e eu entrei no Pronatec. (D2).

O motivo principal foi a questão da Agricultura Familiar. Eu sempre gostei muito de agricultura familiar e como eram pessoas carentes que necessitavam de mais conhecimento sobre a área e eu sempre me dediquei nessa área, eu resolvi entrar no PRONATEC (D1).

A questão financeira pra gente pesa bastante e também pela oportunidade da gente aprender uma forma diferente de gerir. [...] E o Pronatec a gente iria começar, porque a gente pegou bem no comecinho. Então era essa possibilidade de empreender algo novo. Isso também foi algo que despertou interesse (G2).

Não existem nos depoimentos dos docentes e gestores críticas ao modelo de ensino profissional proposto pelo Pronatec, também estão ausentes de suas falas críticas aos proventos recebidos através de bolsa ou até mesmo ao frequente atraso do pagamento da mesma, como já mencionamos, os depoimentos eram de professores do IFPE, que não tinham a renda do Pronatec como o pilar de seu orçamento.

\section{Considerações finais}


O Pronatec aponta para uma profissionalização mais aligeirada e desconectada da formação geral. Este tipo de formação profissional é inerente à própria natureza das políticas públicas educacionais no capitalismo. É importante esta compreensão para não cair em uma análise simplista, panfletária e caráter superficial.

\begin{abstract}
A política educacional [...] é um fenômeno que se produz no contexto das relações de poder [...] e portanto no contexto das relações sociais que plasmam as assimetrias, a exclusão e as desigualdades que se configuram na sociedade e no nosso objeto. A questão é tentar o sábio equilíbrio: manter uma postura objetiva que dote o conhecimento produzido de um coeficiente científico, sem abdicar de um nível analítico [...] assim, podemos nos livrar da constante tentação de nos deixar envolver na prática "das denúncias", que pouco contribui para a construção de novos saberes comprometidos com a mudança substantiva da ordem (AZEVEDO, 2001, p. 3-4).
\end{abstract}

O ordenamento do Pronatec no IFPE é um bom exemplo para compreender a execução do Programa e os impactos que este tem junto aos Institutos Federais. O fato de haver uma clara priorização dos cursos FIC, mais aligeirados, a expansão do Instituto não acompanhada da necessária qualidade nos oferece a visão de uma política fortemente capilarizada (presente em todos os campi da Instituição), com um considerável número de alunos mas desconectada com os diferentes cursos tradicionalmente ofertados.

Apesar de toda uma narrativa que defende os governos da Frente Popular (Lula da Silva e Dilma Rousseff) como responsáveis por uma ruptura com o modelo de educação estabelecido ao longo dos anos em nosso país, notadamente o que foi implantado pelo governo de Fernando Henrique Cardoso, as mudanças que aconteceram nos governos do Partido dos Trabalhadores não romperam com a lógica de uma educação voltada à satisfação dos interesses do capital. O que fica bem claro com a reivindicação do Pronatec pelo governo Michel Temer. 


\section{Referências Bibliográficas}

ALVES-MAZOTTI, Alda Judith; GEWANDSZNAJDER, Fernando. O Método nas Ciências Naturais e Sociais: Pesquisa Quantitativa e Qualitativa. São Paulo: Thomsom, 2002.

AZEVEDO, Janete M. Lins de. A educação como política pública. Campinas: Autores Associados, 2001.

BRAGA, Ruy. A política do precariado: do populismo à hegemonia lulista. São Paulo: Boitempo, 2013.

BRASIL. Lei no 11.788, de 25 de setembro de 2008. Disponível em: <http://www.planalto.gov.br/ccivil_03/_ato2007-2010/2008/lei/l11788.htm>. Acesso em: 04 set. 2015.

Lei no 11.892, de 29 de dezembro de 2008. Disponível em: <http://www.planalto.gov.br/ccivil_03/_ato2007-2010/2008/lei/l11892.htm>. Acesso em: 30 mar. 2015.

Lei 12513/11. Disponível em: <http://www.planalto.gov.br/ccivil_03/_ato2011-2014/2011/lei/l12513.htm>. Acesso em: 29 mai. 2015

CGU. RELATÓRIO DE GESTÃO EXERCícIO 2014. Disponível em: <http://www.cgu.gov.br/sobre/auditorias/arquivos/2014/cgu-relatorio-de-gestao2014-publicado-tcu.pdf>. Acesso em: 06 ago. 2015

DUFFY, Brendan. Análise de dados documentais. In: BELL, Judith. Como realizar um projecto de investigação: um guia para a pesquisa em ciências sociais para a educação. Lisboa: Gradiva, 1997. p. 35-37.

FRIGOTTO, Gaudêncio. A produtividade da escola improdutiva. São Paulo: Cortez, 1989.

GADOTTI, Moacir. Concepção dialética da educação. São Paulo: Cortez, 1984.

GOMES, Alexandre Lopes; PALÁCIOS, Paulie Ceres. Desenvolvimento territorial: Possibilidades no diálogo entre o IF Goiano- Campus Ceres e o PRONATEC. II Simpósio de pesquisa e extensão de Ceres e Vale de São Patrício 04 a 07 de Novembro de 2014 - UEG Campus Ceres - GO. Anais... Disponível em < http://www.anais.ueg.br/index.php/simpec/article/view/3579> Acesso em 01.nov.2015.

GRAMSCI, Antonio. Cartas desde la cárcel. Madrid: Cuadernos para el diálogo, 1978. 
IFPE. Plano de Curso Técnico em Alimentos (Pronatec). Vitória de Santo Antão, 2012.

IFPE. Plano de Curso Técnico em Segurança do Trabalho (Pronatec). Vitória de Santo Antão, 2012.

IFPE. Relatório de Gestão do Exercício 2014. Recife, 2015.

IFPE. Regimento Interno das Ações da Bolsa Formação do PRONATEC no IFPE. Recife, 2014.

KUENZER, Acacia. Pedagogia da fábrica: as relações de produção e educação do trabalhador. São Paulo: Cortez, 1985. GORZ. André. Crítica da divisão do trabalho. São Paulo: Martins Fontes, 1980.

POSSA, André Dala; KUBA, Cristina Missao Borille ; JACQUES, Eliane de Souza. O Pronatec e a extensão tecnológica nos Institutos Federais de Educação: contribuições para o ensino. Caminho Aberto, Florianópolis, n.1, p. $1-14,2014$.

SILVA, Yuri César et al. Estudo Técnico n. 09/2015. Análise do perfil dos desistentes e concluintes do Pronatec Bolsa Formação. 2015. In: MONTAGNER, Paula et al (org.). Cadernos de Estudos Desenvolvimento Social em Debate N. 24. Inclusão produtiva urbana: o que fez 0 Pronatec/Bolsa Formação entre 2011 e 2014. 2015.

TRIVIÑOS, Augusto Nibaldo Silva. Introdução à Pesquisa em Ciências Sociais: a Pesquisa Qualitativa em Educação. São Paulo: Atlas, 1989.

Recebido em: 7 de novembro de 2017. Aprovado em: 28 de novembro de 2017.

Publicado em: 31 de janeiro de 2018. 